\title{
Sildenafil citrate to improve colour doppler indices in patient with pre-eclampsia-a path less taken
}

\author{
Priyanka H. Vora*, Rana A. Choudhary, Kedar N. Ganla
}

Department of Reproduction, Ankoor Fertility Clinic, Mumbai, Maharashtra, India

Received: 01 September 2020

Accepted: 17 October 2020

\section{*Correspondence:}

Dr. Priyanka H. Vora,

E-mail:priyav865@gmail.com

Copyright: (c) the author(s), publisher and licensee Medip Academy. This is an open-access article distributed under the terms of the Creative Commons Attribution Non-Commercial License, which permits unrestricted non-commercial use, distribution, and reproduction in any medium, provided the original work is properly cited.

\section{ABSTRACT}

Presented a case of high-risk pregnancy of an elderly primigravida who had abnormal colour doppler indices. Addition of sildenafil citrate lead to improvement of colour doppler indices and growth parameters, thus prolonging the period of gestation by 6 weeks. This led to decreased neonatal ICU stay and reduction in neonatal morbidity.

Keywords: Vaginal sildenafil citrate, Preterm, Pregnancy induced hypertension, Absent end diastolic flow, Colour doppler indices

\section{INTRODUCTION}

Adequate blood flow in uteroplacental vascular function is essential to achieve optimal fetal growth. Abnormal vasculature adaptation during embryogenesis and placentation resulting in aberrant blood flow, has been implicated as a possible cause of abnormal colour doppler

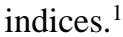

\section{CASE REPORT}

A 38-year-old primigravida with poor ovarian reserve, history of one failed self in vitro fertilization (IVF) cycle and treated genital Koch's conceived with donor oocyte IVF. She was on Aspirin $150 \mathrm{mg}$ and 40 units of low molecular weight heparin post embryo transfer in view of absent blood flow in zone 3 and 4 according to Applebaum's staging and the same were continued in pregnancy. Her nuchal thickness ultrasonography (NT scan) at 12.2 weeks of gestation was negative for any anomalies but showed bilateral uterine arteries with diastolic notch and increased resistance. Her level 3 ultrasound at 18 weeks of gestation did not show any major malformation. However, uterine artery mean PI was increased to 1.95 (normal range up to 1.4). Bilateral uterine arteries showed increased resistance (right-1.5 and left-2.4). Fetal 2D echo at 24 weeks of gestation showed increased S/D ratio of the left uterine artery to 9.3. Intensive monitoring was done biweekly and she was started on nitric oxide donor (L-arginine) $3 \mathrm{gm}$ daily. However, at 28 weeks of gestation she developed pregnancy induced hypertension (PIH) and was started on tablet labetalol $100 \mathrm{mg}$ thrice a day. Her colour doppler ultrasound showed estimated baby weight (EBW) of $1.133 \mathrm{~kg}$ with normal amniotic fluid index (AFI) but absent diastolic flow (Figure 1). Started her on tablet sildenafil citrate $25 \mathrm{mg}$ vaginally thrice a day after counseling the patient and her husband. Injection betamethasone 2 doses were given. She was monitored daily for blood pressure and fetal kick count. Weekly serial colour doppler indices were performed. At 30 weeks of gestation her blood pressure was risen with trace urinary albumin but normal liver, kidney function tests and coagulation profile. So, increased the dose of labetalol to $200 \mathrm{mg}$ TDS. But as there was no further deterioration in the doppler indices and IUGR, sildenafil was continued. Further ultrasound done at 32 weeks of gestation showed improvement in the doppler parameters with bilateral uterine and umbilical arteries showing increased resistance with S/D of 6.9 and 5.5 respectively. The umbilical artery diastole was preserved and EBW was $1.401 \mathrm{~kg} \pm 205 \mathrm{gm}$ and AFI of $11.4 \mathrm{~cm}$. However, the 
abdominal circumference was $<10^{\text {th }}$ centile suggesting fetal growth retardation. A repeat ultrasound at 33 weeks showed mild oligohydramnios of $8.2 \mathrm{~cm}$ with similar doppler indices (Figure 2). Bed rest and adequate hydration was continued. However, ultrasound at 34 weeks of gestation showed absent end diastolic flow and a decision for emergency cesarean was taken owing to worsening preeclampsia. She delivered male child of 1.5 $\mathrm{kg}$ with an APGAR score of 8/10, 9/10. The neonate has an uneventful neonatal ICU course of 4 weeks and was transferred back to the mother.

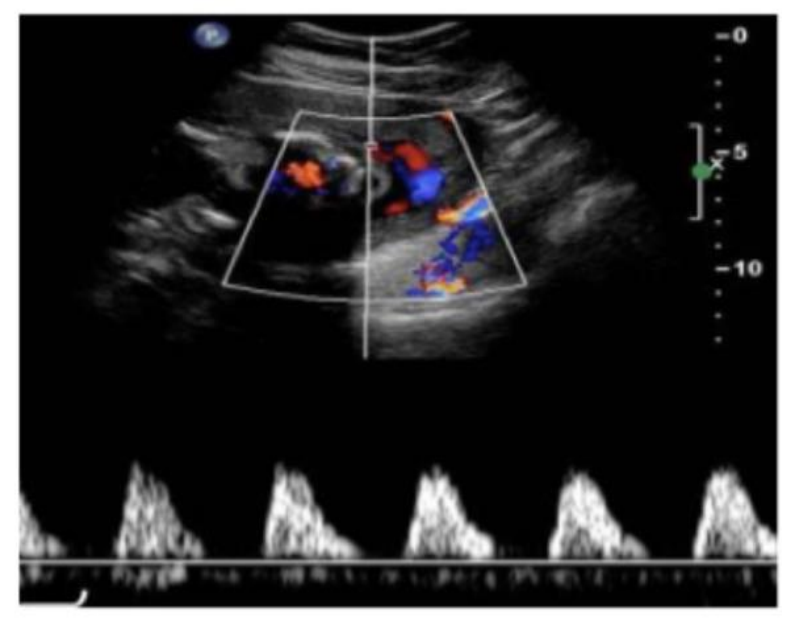

Figure 1: Absent end diastolic flow at 28 weeks of gestation.

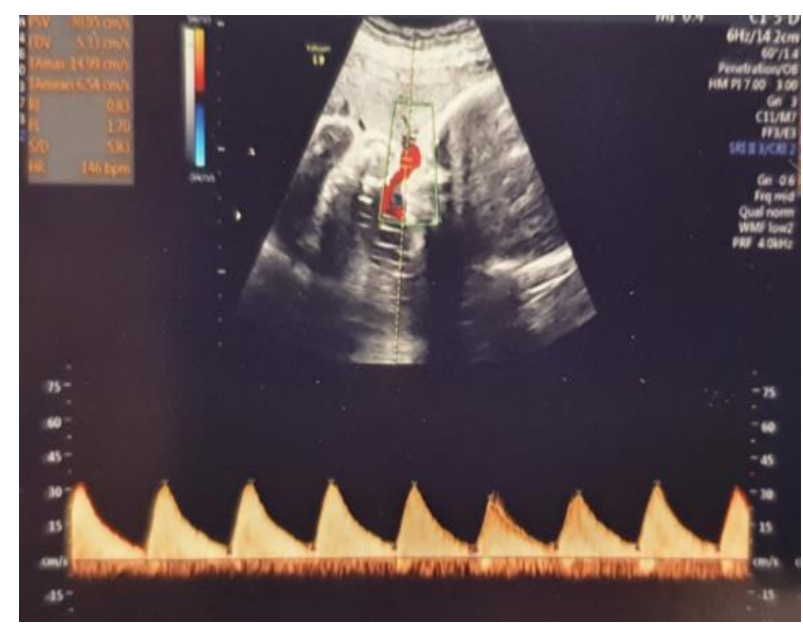

Figure 2: Increased S/D ratio of umbilical artery at 33 weeks of gestation.

\section{DISCUSSION}

Antenatal women who are diagnosed with growth restricted fetuses usually mimic the population of preeclampsia in having increased resistance in maternal arteries. ${ }^{1}$ In events that occur in the natural course of pregnancy, the trophoblast produces nitric oxide (NO) responsible for vasodilation which occurs in the fetoplacental circulation. $^{2}$ Uteroplacental blood flow forms the clincher to achieve optimal fetal growth. Abnormal vasculature adaptation results in aberrant blood flow which leads to intrauterine growth retardation. An important factor is the placental bed having insufficient or incomplete trophoblastic invasion of the spiral arteries. $^{3}$ Treatment of the fetus in situ for having abnormal doppler indices must be decided up to its maturity. Hence, if the fetus has attained maturity, one can plan on delivery can be planned as not much is gained with pregnancy continuation. However, in the immature fetus close monitoring is necessary. ${ }^{4}$ Since there is a growing body of evidence in the use of sildenafil, used the same. Sildenafil citrate increases NO production, it being a selective inhibitor of cyclic guanosine monophosphate (cGMP) specific phosphodiesterase type 5 (PDE5). This in turn leads to vascular smooth muscle relaxation, reduction in maternal peripheral resistance and vasoconstriction. It also plays a role in uteroplacental perfusion by vasodilating the myometrial small artery which causes better oxygen supply and nutrition to the fetus. Its role is widening in not only growth restricted fetuses by improving the colour doppler indices but also in pre-eclampsia. ${ }^{5}$ In a study conducted by Premalatha et al $30 \%$ patients were able to have an improvement in the doppler parameters who presented with absent diastolic flow. Further on the effect of sildenafil citrate on isolated resistant arteries with growth retarded fetus was more marked, justifying the role of this drug in women with pre-eclampsia. ${ }^{6}$ The vaginal route can eliminate systemic side effects when compared to its oral route of administration with high drug concentration in the organ of desire. Studies have shown improvements in the birth weight and amniotic fluid levels as in addition to the above it also potentiates estrogen induced vasodilation. ${ }^{7}$ No teratogenic effects have been found in the study conducted by Marzieh et al. In this case, tiding over the doppler indices widened the window period for intrauterine growth which decreased the extrauterine neonatal ICU period and morbidity.

\section{CONCLUSION}

Sildenafil citrate in this case proved beneficial in changing the uteroplacental waveforms on doppler study. In utero gained time even after an absent end diastolic flow helped to reduce the complications associated with extreme prematurity. Sildenafil must be considered in cases of abnormal colour indices where no genetic factor of growth retardation or infection is involved.

\section{Funding: No funding sources \\ Conflict of interest: None declared \\ Ethical approval: Not required}

\section{REFERENCES}

1. Dastjerdi MV, Hosseini S, Bayani L. Sildenafil citrate and uteroplacental perfusion in fetal growth restriction. J Res Med Sci. 2012;17(7):632-6. 
2. Anwar MHH, Hasanin MK, Abdelaziz BR, Ismail Hamd OAM. Effect of Sildenafil Citrate on Fetal Color Doppler Study and Biophysical Profile in Cases of Intrauterine Growth Restriction (IUGR) in Third Trimester. Egyp J Hospital Med. 2018;72(11):5571-4.

3. Ganla KN, Choudhary RA, Desai KN, Kadam SB, Arunachalam K. A retrospective interventional study for evaluation of efficacy and safety of sildenafil citrate in improving intrauterine growth restriction and oligohydramnios using ultrasound Doppler velocimetry. Int J Basic Clin Pharmacol. 2019;8(12):2736-40.

4. Usha K, Sarita B. Placental Insufficiency and Fetal Growth Restriction. J Obstet Gynecol India. 2011;61(5):505-11.

5. Samangaya RA, Mires G, Shennan A, Skillern L, Howe D, McLeod A et al. A randomised, double- blinded, placebo-controlled study of the phosphodiesterase type 5 inhibitor sildenafil for the treatment of preeclampsia. Hypertens Preg. 2009;28:369-82.

6. Premalatha HL, Raghupathi KMS, Srinivas DNB, Venkatesh, Laxmi kanth. Study of effect of sildenafil citrate in pregnant women with intrauterine growth restriction/oligohydramnios. Int J Reprod Contracept Obstet Gynecol. 2016;5(9):3094-7.

7. Farooq SU, Mir SA, Kareem O, Rashid R, Ara R, Bader GN. Sildenafil Citrate in Management of Intrauterine Growth Restriction: A Case Study. J Gynecol Wom Heal. 2019:15(2):555910.

Cite this article as: Vora PH, Choudhary RA, Ganla KN. Sildenafil citrate to improve colour doppler indices in patient with pre-eclampsia-a path less taken. Int J Reprod Contracept Obstet Gynecol 2020;9:5124-6. 